\title{
First cytogenetic characterization of a species of the arboreal ant genus Azteca Forel, 1978 (Dolichoderinae, Formicidae)
}

\author{
Danon Clemes Cardoso, ${ }^{1,2}$, Maykon Passos Cristiano ${ }^{1,2}$, \\ Luísa Antônia Campos Barros ${ }^{1,2}$, Denilce Meneses Lopes², \\ Silvia das Graças Pompolo
}

I Programa de Pós-graduação em Genética e Melhoramento, edifício Arthur Bernardes, subsolo sala 12, Universidade Federal de Viçosa, Viçosa, Minas Gerais, 36570-000, Brazil 2 Departamento de Biologia Geral, Av. Peter Henry Rolfs s/n, Universidade Federal de Viçosa, Viçosa, Minas Gerais, 36570-000, Brazil

Corresponding author: Danon Clemes Cardoso (danon.cardoso@ufv.br)

Academic editor: V. Gokhman | Received 20 November 2011 | Accepted 30 January 2012 | Published 16 March 2012

Citation: Cardoso DC, Cristiano MP, Barros LAC, Lopes DM, Pompolo SdG (2012) First cytogenetic characterization of a species of the arboreal ant genus Azteca Forel, 1978 (Dolichoderinae, Formicidae). Comparative Cytogenetics 6(2): 107-114. doi: 10.3897/CompCytogen.v6i2.2397

\begin{abstract}
In this paper we present, for the first time, a detailed karyotype characterization of a species of the genus Azteca (Dolichoderinae, Formicidae). Cerebral ganglia from Azteca trigona Emery, 1893 were excised and submitted to colchicine hypotonic solution and chromosomal preparations were analyzed through conventional staining with Giemsa, C-banding, silver nitrate staining $\left(\mathrm{AgNO}_{3}\right)$ and sequential base-specific fluorochromes. The analysis shows that $A$. trigona has a diploid number of 28 chromosomes. The karyotype consists of five metacentric pairs, seven acrocentric pairs and two pseudo-acrocentric pairs, which represents a karyotype formula $2 \mathrm{~K}=10 \mathrm{M}+14 \mathrm{~A}+4 \mathrm{~A}^{\mathrm{M}}$ and a diploid number of the arms $2 \mathrm{AN}=38$. The analysis of heterochromatin distribution revealed a positive block on distal region of the short arm of fourth metacentric pair, which was coincident with $\mathrm{Ag}-\mathrm{NOR}$ band and $\mathrm{CMA}_{3}$ fluorochrome staining, meaning that rDNA sequences are interspaced by GC-rich base pairs sequences. The C-banding also marked short arms of other chromosomes, indicating centric fissions followed by heterochromatin growth. The karyotype analysis of $A$. trigona allowed the identification of cytogenetic markers that will be helpful in a difficult taxonomic group as Azteca and discussion about evolutionary aspects of the genome organization.
\end{abstract}

\section{Keywords}

karyotype, chromosome number, chromosome banding, ants, Azteca trigona

Copyright Danon Clemes Cardoso et al. This is an open access article distributed under the terms of the Creative Commons Attribution License 3.0 (CC-BY), which permits unrestricted use, distribution, and reproduction in any medium, provided the original author and source are credited. 


\section{Introduction}

The subfamily Dolichoderinae presents a great diversity of species throughout the world. Species are distributed in different biogeographic regions, from the Palearctic, Nearctic, Afrotropical region and Malaysia, to the Middle East, Australian and Neotropical regions (Bolton 1994). This subfamily comprises 22 genera, of which ten are found in Brazil, and Azteca Forel, 1878 and Dolichoderus Lund, 1831 form the two most diverse genera (Cuezzo, 2003). The species of this subfamily represent a common group, but rather inconspicuous of Neotropical ant fauna compared to other more evident groups (Wild 2009, Cardoso and Cristiano 2010). One of the best known species of Dolichoderinae is the ant Linepithema humile (Mayr, 1868). This is one of the principal invasive ant species and now occurs in more than 15 countries (Diehl-Fleig and Diehl 2007, Wild 2009).

The genus Azteca is strictly Neotropical and very diverse, including around 130 species. They are essentially arboreal and many species have mutualistic associations with particular plant species, where the genus Cecropia presents the most conspicuous association (Longino 1991). Taxonomic reviews of the genus are scarce, regional or restricted to specific groups (Longino 2007) and the absence of a more comprehensive taxonomic review of the genus is the main obstacle for understanding the evolutionary basis of the Azteca-Cecropia mutualistic relationship.

Cytogenetic characterization offers some of the most reliable taxonomic criteria for some groups of organisms and recently, the application of cytogenetic studies focused on understanding the distribution pattern and evolution of species seems very promising (Mariano et al. 2012). In general, the parameters used in these studies are the number of chromosomes, their morphology, amount of heterochromatin, as well as their composition and the base pairs, obtained by chromosome banding techniques. Extensive information on chromosomes of the order Hymenoptera is available, especially the Formicidae of which there are already many known karyotypes. However cytogenetic information is lacking for a great part of known species. At least 750 from more than 12000 species have been cytogenetically studied (Lorite and Palomeque 2010), and the variation in chromosome number is enormous, ranging from $2 \mathrm{n}=2$ to $2 \mathrm{n}=120$ (Mariano et al. 2008). This variation can provide trustworthy cytotaxonomic markers for evolutionary studies in association with chromosome banding. At least 16 genera of the subfamily Dolichoderinae have their chromosome numbers available (Lorite and Palomeque 2010), where the genus Iridomyrmex Mayr, 1862 is the most studied (including the species Iridomyrmex humile, now relocated to the genus Linepithema Mayr, 1866 (Wild 2009)). The chromosome number in Dolichoderinae is less variable than in other related subfamilies, ranging from $2 n=10$ to $2 n=48$ (Lorite and Palomeque 2010). Within genera, the chromosome number varies from $2 \mathrm{n}=14$ to 48 in Iridomyrmex and represents the largest variation found in the subfamily, while, Dolichoderus showed karyotypes ranging from $2 \mathrm{n}=18$ to 30 (Imai et al. 1984a, b).

Even with the immense diversity of species of the genus Azteca, including approximately 130 described species, no cytogenetic study is encountered for this genus. Thus, 
to contribute to the increased cytogenetic knowledge of Formicidae and further understanding of karyotype evolution, the present study aimed to characterize the karyotype of Azteca trigona Emery, 1893, whereas karyotypes of the genera Anillidris Santschi, 1936 and Liometopum Mayr, 1861 remain totally unknown.

\section{Material and methods}

Thirty specimens from two colonies of Azteca trigona collected in Ponte Nova $\left(20^{\circ} 25^{\prime} \mathrm{S}\right.$, $\left.42^{\circ} 54^{\prime} \mathrm{W}\right)$ and Viçosa $\left(20^{\circ} 45^{\prime} \mathrm{S}, 42^{\circ} 52^{\prime} \mathrm{W}\right), \mathrm{MG}$, Brazil were analyzed. The colonies were collected in the field and transferred to a plastic container and maintained in a BOD (Biochemical Oxygen Demand) incubator at $25^{\circ} \mathrm{C}$ following the protocol described by Cardoso et al. (2011) and fed with honey in order to obtain larvae in the pre-pupa stage (post-defecating larvae). The specimens were identified by specialists and Vouchers of the samples collected in this work were deposited in CEPLAC and MZUSP.

Cytogenetic analysis was performed using cerebral ganglia of the larvae selected. Metaphase chromosomes were obtained according to the methodology proposed by Imai et al. (1988). Preparations obtained from fifteen individuals per colony were analyzed. The preparations were stained with Giemsa diluted in Sörensen buffer at (4\%) for 20 minutes. On average, ten metaphases were analyzed per slide and ten slides were submitted to banding techniques. C-banding was performed by BSG method (Barium hydroxide/Saline/Giemsa) according to Sumner (1972). The protocol of Schweizer (1980) was used for preparation of sequential fluorochrome staining $\left(\mathrm{CMA}_{3} / \mathrm{DA} /\right.$ DAPI). Identification of nucleolus organizer regions (NOR) was performed according to Howell and Black (1980). The best metaphases were photographed using an Olympus BX60 microscope equipped with a camera Q color 3 Olympus. Brightness and contrast of the karyotypes were optimized using Photoshop CS4. The karyotypes were mounted in Corel Draw 13 image editing software. Karyotype structure was described according to the nomenclature proposed by Imai (1991) and Levan et al. (1964). For mounting of the karyotypes, the chromosomes were sorted into three groups: metacentric chromosomes $(\mathrm{M})$, acrocentric chromosomes (A) with heterochromatin located across the length of the short arm of the chromosomes, and pseudo-acrocentric chromosomes $\left(\mathrm{A}^{\mathrm{M}}\right)$ which possess a long heterochromatic arm (Imai 1991).

\section{Results and discussion}

The chromosome number observed for Azteca trigona was $2 \mathrm{n}=28$ (Figure 1). The karyotype of this species consists of five metacentric pairs (M), seven acrocentric pairs and two pseudo-acrocentric pairs $\left(\mathrm{A}^{\mathrm{M}}\right)$ according to the terminology proposed by Imai (1991). Considering this chromosome classification, the karyotype formula found for the diploid set would be $2 \mathrm{~K}=10 \mathrm{M}+14 \mathrm{~A}+4 \mathrm{~A}^{\mathrm{M}}$. Thus, the diploid number of the arms according to Imai et al. (1994) was $2 \mathrm{AN}=38$. However, considering Levan et al. (1964), 

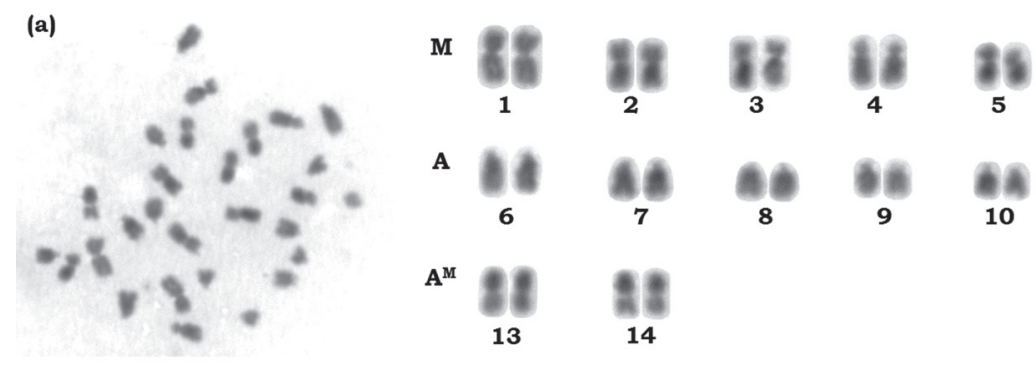

$\mathbf{A}$
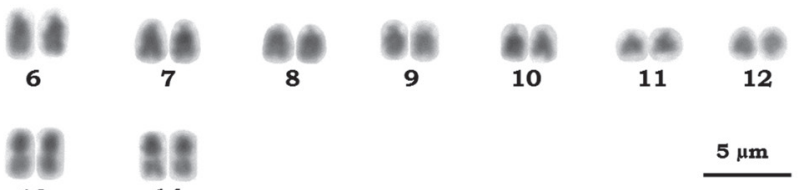

(10)

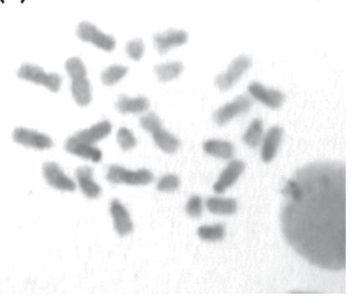

$\mathbf{A}^{\mathbf{M}}$

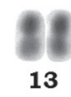

$\mathbf{M}$

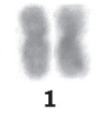

$\mathbf{A}$

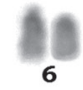

$\mathbf{A}^{\mathbf{M}}$
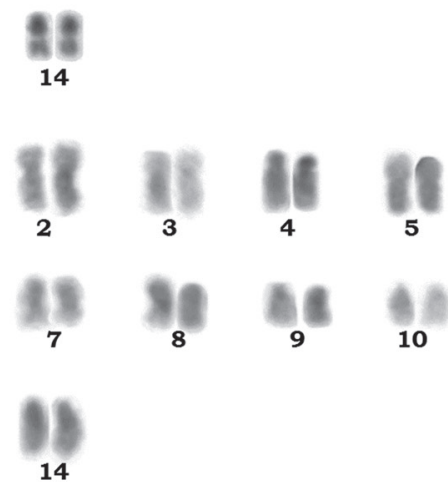

Figure I. Karyotype of female workers of Azteca trigona $2 \mathrm{n}=28$ sorted according to the classification proposed by Imai (1991) a Conventional staining using Giemsa b C-banding showing the distribution of heterochromatin.

the arm ratio analysis results in five pairs of metacentric (pairs 1,2,3, 13 and 14), two pairs of submetacentric (pairs 4 and 5) and 7 pairs of subtelocentric (pairs 6 to 12). It is important to emphasize that the chromosome classification by Levan et al. (1964) is the most used in cytogenetic studies of Formicidae (Lorite and Palomeque 2010), although classification proposed by Imai (1991) is more informative from an evolutionary view. It was not possible to observe the haploid karyotype (n) since there was no production of alates (reproductive individuals) during the maintenance period of the colony.

Of the subfamilies of Formicidae, Dolichoderinae is the fourth subfamily with the major number of taxa studied. According to Lorite and Palomeque (2010), about 50 taxa in 16 genera have been studied. The diploid karyotype of Dolichoderinae varied from 10 chromosomes in Tapinoma indicum Forel, 1895 and T. melanocephalum (Fabricius, 1793) (Imai et al. 1984a), up to 48 chromosomes in Iridomyrmex anceps (Roger, 1863) (Imai et al. 1984b). However, the latter chromosome number has been questioned due to the great discrepancy from other karyotypes described to subfamily (Lorite and Palomeque 2010). The chromosome number of Azteca, $2 \mathrm{n}=28$, seems consistent with the karyotypic variation of the subfamily, which according to Crozier (1970) and Imai et al. (1977) is characterized by a low to average chromosome number.

Results of the banding techniques indicate positive C-, Ag-NOR and $\mathrm{CMA}_{3}$-bands, and negative DAPI-bands on the short arm of the fourth pair of metacentric chromosomes (Figs 1-3), indicating that this region is rich in heterochromatin and should correspond to the nucleolus organizer region (NOR) (Fig. 3). This chromosome pair was $\mathrm{CMA}_{3}$-positive and DAPI-negative, indicating that the marked regions are rich in GC 

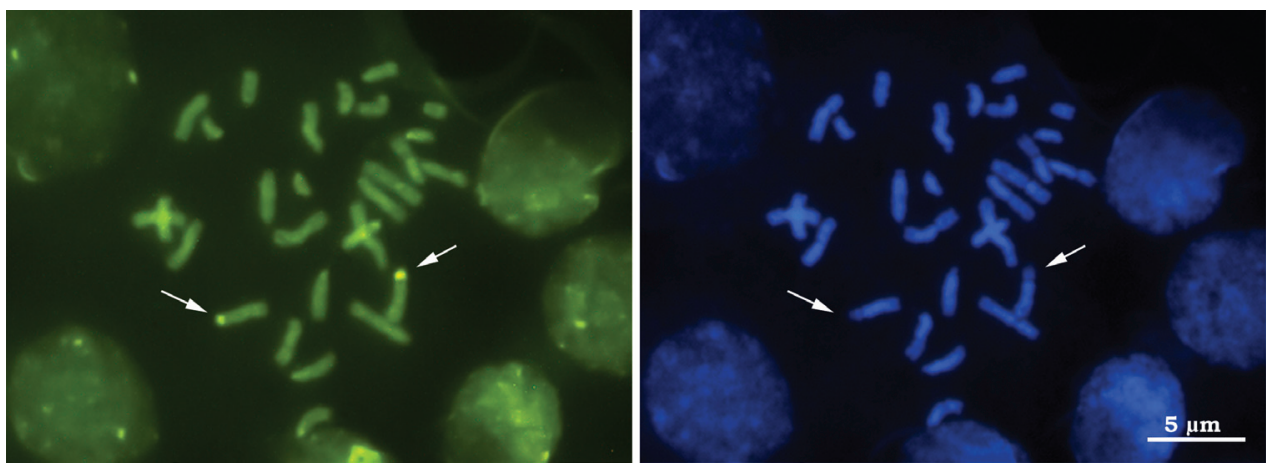

Figure 2. Diploid metaphase of Azteca trigona submitted to sequential staining with fluorochromes $\mathrm{CMA}_{3} / \mathrm{DA} / \mathrm{DAPI}$ a Staining with $\mathrm{CMA}_{3}$, arrows indicate the fourth chromosome pair and the $\mathrm{GC}^{+}$regions $\mathbf{b}$ Staining with DAPI, arrows indicate the same chromosome pair with the negative AT-rich regions.

bases and devoid of AT bases (Fig. 2). Several authors have reported that CG-positive and AT-negative (i.e. auto-complementary) regions are related to nucleolus organizer regions (NORs). This relationship has been reported in grasshoppers (Camacho et al. 1991), bees of the genus Melipona (Illiger, 1806) (Rocha et al. 2002) as well as in other neotropical bees (Rocha et al. 2003; Brito et al. 2003) and in ants Dinoponera lucida Emery, 1901 (Mariano et al. 2008) and Tapinoma nigerrimum (Nylander, 1856) (Lorite et al. 1997), where the latter belongs to the same subfamily of ants as $A$. trigona. In addition, in many studies homology between the Ag-NOR positive regions and probes specific to NORs was revealed by means of the in situ hybridization technique (Lorite et al. 1997, Rocha et al. 2002, Mariano et al. 2008). Since this technique uses specific probes, it is much more sensitive to detection of NORs and provides consistent data on the relationships between banding patterns - C-bands, Ag-NOR and fluorochrome staining.

Furthermore, the silver nitrate staining revealed that the fourth metacentric pair also had an Ag-positive block. This finding corroborated that this pair carried NORs, which were heteromorphic between the homologues (Fig. 3). Heteromorphism in NOR size is frequent in a large number of organisms and can be explained by tandem duplications of the ribosomal genes (Sumner 2003). The NOR heteromorphism found in Azteca trigona probably resulted from the duplication/amplification or unequal crossover during meiosis of some ribosomal sequences of the homologues.

The results presented here are, to our knowledge, the first cytogenetic data of a species of the genus Azteca, and the second known for a species of the subfamily Dolichoderinae in the Neotropics. Previously, cytogenetic data on the species Dorymyrmex pyramicus (Roger, 1863) $(2 \mathrm{n}=18)$ were presented on the base of only five workers collected in Uruguay (Gôni et al. 1983). According to some authors, cytogenetic data on Neotropical ant species are scarce given the immense biodiversity of this region (Goñi et al. 1983, Lorite et al. 1997). Cytogenetic data are important tools that can be used for phylogenetic inferences (Rocha et al. 2002, Lorite and Palomeque 2010) and solving species identification problems (Borges et al. 2004, Delabie et al. 2008). 


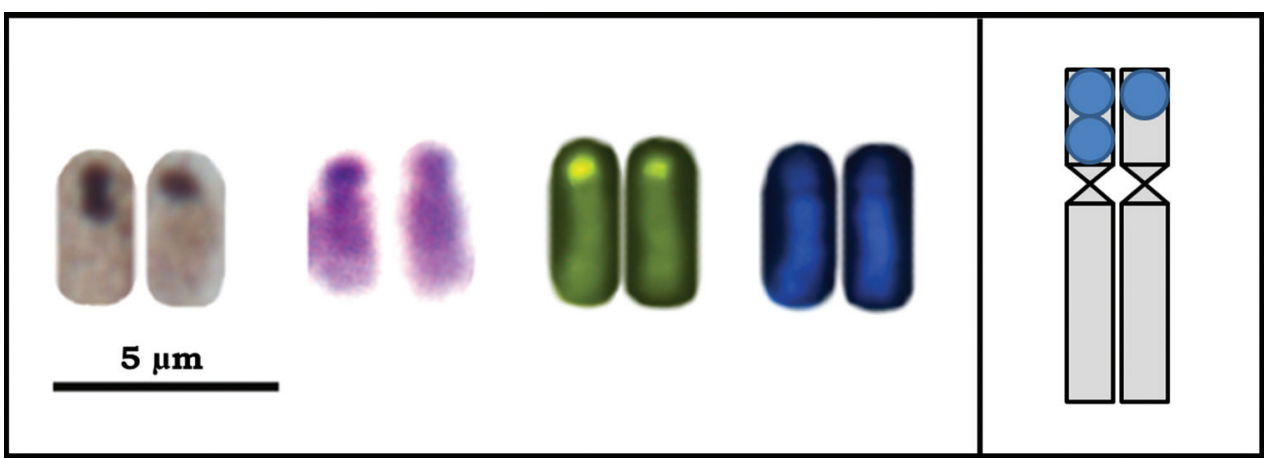

Figure 3. Fourth pair of chromosomes of Azteca trigona submitted to different banding techniques: AgNOR, C-banding and sequential $\mathrm{CMA}_{3} / \mathrm{DA} / \mathrm{DAPI}$ fluorochrome staining. The inserted scheme indicates that for all techniques the homologues are heteromorphic for the banding pattern.

In particular, the genus Azteca presents a great challenge to taxonomists since identification is practically impossible at the species level in absence of the queen (Longino 2007). Since it is hardly possible to identify the species only by workers, it becomes a limiting factor for studies on biology, ecology and biodiversity of the genus, because the workers they are much more abundant in the colony and the queen is not always collected. Cytogenetic data presented herein are the first records for the genus and can be used for the development of cytogenetic markers. These may be used in phylogenetic inference and applied to taxonomy in order to facilitate the identification of species. Increase in the number of samples and application of other banding techniques to acquire cytogenetic patterns typical of the species of the genus are to be conducted for the better understanding of evolution and taxonomy of this group.

\section{Acknowledgements}

The authors are grateful for the critical reading of two anonymous reviewers and Evan Vissar for language reviewing. We also thank Ricardo R. C. Solar for helping us with the ant sampling. This research was supported by Fundação de Amparo à Pesquisa do Estado de Minas Gerais (FAPEMIG) and Coordenação de Aperfeiçoamento de Pessoal de Nível Superior (CAPES). We also thank Rodrigo Feitosa and Jacques H.C. Delabie for taxonomic identification.

\section{References}

Bolton B (1994) Indentification guide to the ant genera of the world. Harvard University Press, Cambridge, 232 pp.

Borges DS, Mariano CSF, Delabie JHC, Pompolo SG (2004) Estudos citogenéticos em formigas neotropicais do gênero Gnamptogenys Roger (Hymenoptera, Formicidae, Ec- 
tatomminae). Revista Brasileira de Entomologia 48: 481-484. doi: 10.1590/S008556262004000400009

Brito RM, Caixeiro APA, Pompolo SdG, Azevedo GG (2003) Cytogenetic data of Partamona peckolti (Hymenoptera, Apidae, Meliponini) by $\mathrm{C}$ banding and fluorochrome staining with $\mathrm{DA}_{\text {CMA }}$ and DA/DAPI. Genetics and Molecular Biology 26: 53-57. doi: 10.1590/ S1415-47572003000100009

Camacho JPM, Cabrero J, Viseras E, Lopez-Leon MD, Navas-Castillo J, Alche JD (1991) G-banding in two species of grasshopper and its relationship to $\mathrm{C}, \mathrm{N}$, and fluorescence banding techiques. Genome 34: 638-643. doi: 10.1139/g91-097

Cardoso DC, Cristiano MP (2010) Myrmecofauna of the southern Catarinense Restinga sandy coastal plain: new records of species occurrence for the State of Santa Catarina and Brazil. Sociobiology 55: 229-239.

Cardoso DC, Cristiano MP, Tavares MG (2011) Methodological remarks on rearing basal Attini ants in the laboratory for biological and evolutionary studies: overview of the genus Mycetophylax. Insectes Sociaux 58: 427-430. doi: 10.1007/s00040-011-0160-3

Crozier RH (1970) Karyotypes of twenty-one ant species (Hymenoptera; Formicidae), with reviews of the known ant karyotypes. Canadian Journal of Genetics and Cytology 12: 109-128.

Cuezzo F (2003) Subfamilia Dolichoderinae. In: Fernández F (Ed) Introducción a las hormigas de la región Neotropical. Instituto de Investigación de Recursos Biológicos Alexandre von Humbolt, Bogotá, Colombia, 424.

Delabie JHC, Mariano CSF, Mendes LF, Pompolo, SG, Fresneau, D (2008) Problema apontados por estudos morfológicos, ecológicos e citogeneticos no gênero Pachycondyla na região neotropical: o caso do complexo apicalis. In: Vilela E, Santos IA, Schoereder JH, Serrão JE, Campos LAO, Lino-Neto J (Eds) Insetos Sociais - da biologia a aplicação. Editora UFV, Viçosa, Brazil, 442.

Diehl-Fleig E, Diehl E (2007) Organização social e status de praga da formiga argentina Linepithema humile (Mayr 1868) no Rio Grande do Sul. O Biológico 69: 31-34.

Goñi G, Zolessi LC, Imai HT (1983) Karyotype of thirteen ant species from Uruguay (Hymenoptera - Formicidae). Caryologia 36: 363-371.

Howell WM, Black DA (1980) Controlled silver staining of nucleolus organizer regions with a protective colloidal developer: a 1-step method. Experientia 36: 1014-1015. doi: 10.1007/ BF01953855

Imai HT (1991) Mutability of constitutive heterochromatin (C-bands) during eukaryotic chromosomal evolution and their cytological meaning. Japanese Journal of Genetics 66: 635-661. doi: 10.1266/jjg.66.635

Imai HT, Crozier RH, Taylor RW (1977) Karyotype evolution in Australian ants. Chromosoma 59: 341-393. doi: 10.1007/BF00327974

Imai HT, Taylor RW, Crosland MWJ, Crozier RH (1988) Modes of spontaneous evolution in ants with reference to the minimum interaction hypothesis. Japanese Journal of Genetics 63: 159-185. doi: 10.1266/jjg.63.159

Imai HT, Taylor RW, Crozier RH (1994) Experimental bases for the minimum interaction theory. I. Chromosome evolution in ants of the Myrmecia pilosula species complex (Hymenoptera: Formicidae: Myrmeciinae). Japanese Journal of Genetics 69: 137-182. doi: 10.1266/jjg.69.137 
Imai HT, Urbani CB, Kubota M, Sharma GP, Narasimhanna MN, Das BC, Sharma AK, Sharma A, Deodikar GB, Vaidya VG, Rajasekarasetty MR (1984a) Karyological survey of Indian ants. Japanese Journal of Genetics 59: 1-32. doi: 10.1266/jjg.59.1

Imai HT, Kubota M, Brown-Jr. WL, Ihara M, Tohari M, Pranata RI (1984b) Chromosome observations on tropical ants from Indonésia. Annual Report of National Institute of Genetics 35: 46-48.

Levan A, Fredga K, Sandberg AA (1964) Nomenclature for centromeric position on chromosomes. Hereditas 52: 201-220. doi: 10.1111/j.1601-5223.1964.tb01953.x

Longino JT (1991) Azteca ants in Cecropia trees: Taxonomy, colony structure, and behaviour. In: Huxley CR, Cutler DF (Eds) Ant-Plant Interactions. Oxford University Press, Oxford, 271-288.

Longino JT (2007) A taxonomic review of the genus Azteca (Hymenoptera : Formicidae) in Costa Rica and a global revision of the aurita group. Zootaxa 1491: 1-63.

Lorite P, Aranega AE, Luque F, Palomeque T (1997) Analysis of the nucleolar organizing regions in the ant Tapinoma nigerrimum (Hymenoptera, Formicidae). Heredity 78: 578582. doi: $10.1038 /$ hdy. 1997.96

Lorite P, Palomeque T (2010) Karyotype evolution in ants (Hymenoptera: Formicidae), with a review of the known ant chromosome numbers. Myrmecological News 13: 89-102.

Mariano CDSF, Pompolo SDG, Campos Barros LA, Mariano-Neto E, Campiolo S, Charles Delabie JH (2008) A biogeographical study of the threatened ant Dinoponera lucida Emery (Hymenoptera: Formicidae: Ponerinae) using a cytogenetic approach. Insect Conservation and Diversity 1: 161-168. doi: 10.1111/j.1752-4598.2008.00022.x

Mariano CDSF, Pompolo SDG, Silva JG, Delabie JHC (2012) Contribution of cytogenetics to the debate on the paraphyly of Pachycondyla spp. (Hymenoptera, Formicidae, Ponerinae). Psyche 2012: 1-9.

Rocha MP, Pompolo SD, Dergam JA, Fernandes A, Campos LAD (2002) DNA characterization and karyotypic evolution in the bee genus Melipona (Hymenoptera, Meliponini). Hereditas 136: 19-27. doi: 10.1034/j.1601-5223.2002.1360104.x

Rocha MP, Pompolo SG, Campos LAO (2003) Citogenética da tribo Meliponini (Hymenoptera, Apidae). In: Melo GAR, Alves-dos-Santos I (Eds) Apoidea Neotropica: Homenagem aos 90 Anos de Jesus Santiago Moure. UNESC, Criciúma, Brazil, 311-320.

Schweizer D (1980) Simultaneous fluorescent staining of R bands in a specific heterochromatin regions (DA/DAPI - bands) in human chromosomes. Cytogenetics and Cell Genetics 27: 190-193. doi: 10.1159/000131482

Sumner AT (1972) A simple technique for demonstrating centromeric heterochromatin. Experimental Cell Research 75: 304-306.

Sumner AT (2003) Chromosomes: Organization and Function. Blackwell Publishing, North Berwick, United Kingdom, 287 pp. doi: 10.1016/0014-4827(72)90558-7

Wild AL (2009) Evolution of the Neotropical ant genus Linepithema. Systematic Entomology 34: 49-62. doi: 10.1111/j.1365-3113.2008.00435.x 